\title{
Las enfermedades infecciosas en el hombre y su prevención a lo largo del tiempo
}

\section{Infectious diseases in humans and their prevention over time}

\author{
Rolando Neri-Vela* \\ Escuela Médico Naval, Ciudad de México, México
}

Los padecimientos causados en el hombre por diversos microorganismos han sido un gran problema en la historia; la peste, la viruela, la tuberculosis, el sarampión, etc., han puesto en juego el ingenio de la mente humana para prevenir al ser humano de ellas.

Trataré solo de una muestra de estos males.

Antes del descubrimiento de América por Cristóbal Colón, en 1492, la peste bubónica, la lepra, la viruela, el cólera, la malaria, eran desconocidas en América, $y$ desde ese entonces las enfermedades se han vuelto cosmopolitas.

La peste ha sido referida en la Biblia; hacia el año 1000 a.C. los hebreos exiliados en Egipto, durante los años que incluían el reinado de Akenatón (o Amenofis IV) (c. 1379 a.C.) habían acuñado la expresión «las diez plagas de Egipto» para designar los desastres causados por langostas, ratas, inundaciones, carestía y enfermedad'.

Se sabe desde la Edad Media que en cuanto se tenían noticias de que una epidemia iba a asolar una región, los habitantes se resguardaban en sus casas para evitar ser contagiados, y el médico que iba a visitar la casa de algún apestado se cubría con sus ropas desde el cuello hasta los tobillos, vestían guantes y sombrero de ala ancha, y se ponía una máscara que a la altura de la nariz y la boca tenía una especie de pico de pájaro, dentro del cual se ponía un trapo empapado de vinagre o alguna sustancia aromática, para evitar el respirar los miasmas que provocaban la enfermedad. Además, portaba gafas, por lo que es una reminiscencia de la vestimenta utilizada por el personal sanitario en la actualidad para atender las salas de afectados por la enfermedad por coronavirus 2019 (COVID-19).

De la peste se conocen dos variantes, la peste bubónica y la neumónica, y a lo largo de la historia se han conocido varios brotes.

Dos médicos que trabajaron en forma independiente para desentrañar su agente causal fueron el japonés Shiba Saburo Kitasato, quien estuviera con Robert Koch en Berlín entre 1886 y 1891, y Alexander Yersin, un discípulo suizo de Louis Pasteur y Émile Roux. Mientras estaban en Hong Kong durante la peste de 1894, ambos descubrieron que el bacilo hoy conocido como Yersinia pestis estaba presente en el tejido de ratas y humanos muertos por la peste. Dos años después, en Bombay, Paul Lewis Simond descubrió que el lazo entre las ratas y el hombre era la pulga Xenopsylla cheopis; aunque otras especies de pulga también pueden transmitir esta enfermedad, se considera que Xenopsylla cheopis es el principal vector de la peste en su forma bubónica'.

Actualmente, con el uso oportuno de antibióticos como la estreptomicina y la tetraciclina la tasa de mortalidad de la peste neumónica es prácticamente de cero, por lo que las vacunas de Haffkine y de Ferrán-Haffkine, que fueron creadas para su prevención, ya están en desuso, pues los casos de peste en la actualidad son por fortuna raros.

Otra de las enfermedades que ha causado grandes estragos en la humanidad es la tuberculosis, que originalmente fue una enfermedad del ganado y de otros 
mamíferos, que se extendió secundariamente al hombre. Desde la domesticación de los animales en el periodo neolítico, la llegada de la infección por tuberculosis bovina en los humanos puede coincidir con la fase de la cría de animales. Un centro de domesticación de ganado en la cuenca noreste del Mediterráneo ocurrió durante el séptimo al sexto milenio a.C. La ordeña del ganado probablemente ocurrió en el quinto milenio a.C. La propagación del ganado infestado al ser humano en gran parte se debió a la ingesta de leche infectada, y esto podría explicar la predominancia de tuberculosis bovina en niños, y no se debe olvidar que también se pudo deber por comer carne de ganado infectada. La evidencia más temprana de la tuberculosis en animales es de origen indio, pues hay una clara evidencia de la enfermedad en elefantes antes del año 2000 a.C. y es conocido que en el Pleistoceno los elefantes de la India se extendieron a través de Mesopotamia hacia los límites del Asia Menor ${ }^{2}$.

Si bien la tuberculosis ha disminuido drásticamente gracias a la medicina preventiva, continúa siendo una amenaza con la aparición del virus de la inmunodeficiencia adquirida y el SIDA, la pobreza y la mendicidad resultante.

En 1882 Robert Koch descubrió el bacilo causante de la tuberculosis, y la vacuna creada por Albert Calmette y Jean-Marie Camille Guérin en 1922 ha salvado muchas vidas humanas, así como evitado seres incapacitados.

Quiero hacer notar que el término gripe proviene del francés (grippe), y significa "garra» 0 "gancho" por el propio simbolismo que tiene el mal al atraparnos y provocar determinados síntomas. Influenza es italiano e indica la «influencia» de factores externos como el aire y la temperatura.

Es posible que un brote gripal haya afectado al ejército griego durante el sitio de Siracusa en 395 a.C., y se piensa que la influenza estuvo presente por todo el Occidente y el Medio Oriente durante el Medioevo. El llamado sudor inglés de 1485 pudo tratarse de una gripe. La primera forma inequívoca de gripe sobre Europa data de 1170, y en fechas posteriores, en 1426-1427 afectó a España, Francia, los Países Bajos y las islas británicas, y es factible que el mal pasase el Océano Atlántico en 1493 con los pasajeros del segundo viaje de Cristóbal Colón a América, ya que tras el atraque del navío ocurrió una gran mortandad entre los indígenas ${ }^{3}$.

La llamada gripe rusa se desarrolló en 1889-1890, y se originó en Turquía, para después invadir Rusia,
Finlandia y poco más tarde Europa, América y el resto del mundo.

Debido a las guerras y sus consecuencias, entre ellas la pobreza, el hambre y el hacinamiento, el tifo fue una enfermedad frecuente, y México no fue la excepción. Ya se habían hecho varias experiencias para obtener una vacuna en contra del tifo; en Alemania, en donde con éxito limitado en 1916 Hamdi usó como vacuna sangre desfibrinada y calentada tomada de pacientes en la fase aguda del tifo, y por la misma época Charles Nicolle en Servia usó suero en vez de sangre. En 1930 Rudolf Weigl en Polonia preparó una vacuna contra el tifo a partir de rickettsias inoculadas experimentalmente en piojos, cuyos intestinos y heces fecales eran molidos y tratados con formaldehído, y a pesar de que se usó en gran escala y con buenos resultados tuvo que suspenderse por ser de preparación complicada y requerir de 100 a 200 piojos por dosis.

Con el mismo fin de tener una vacuna antitifosa, Hans Zinsser entre 1937 y 1939 obtuvo una cantidad razonable de las rickettsias después de inocularlas en la cavidad peritoneal de las ratas. Este método fue mejorado en México por uno de los mejores científicos que ha habido en el país, Maximiliano Ruiz Castañeda, al infectar las vías respiratorias de ratas. Otra contribución de Ruiz Castañeda en el campo del tifo fue el preparar y aplicar una vacuna divalente que incluía tanto a Rickettsia prowaseki como a Rickettsia typhi, agente del tifo murino, ya que en esa época ambos agentes eran altamente prevalentes en México y eran responsables de un alto número de casos $^{4}$.

La pandemia de 1918-1919 es denominada Gripe española, a pesar de que no se originó en España, sino en EE.UU. España, que era neutral en la Primera Guerra Mundial, notificó su presencia. El primer brote se detectó el 4 de marzo de 1918, en un campamento del ejército estadounidense en Funston, Kansas, viajando con el contingente militar de los EE.UU. a Francia. El 1 de abril apareció en el país galo contaminando a la población civil y a todas las fuerzas contendientes. Un mes más tarde estaba activa en regiones como España, Portugal, Italia, Grecia, Albania, Escocia, Norte de África y la Península Balcánica.

La segunda oleada de la gripe española salió de las ciudades de Brest (en Francia) y de Boston (en EE.UU.), así como de Freetown (en Sierra Leona), durante agosto de 1918. A finales de febrero de 1919 estaba invadida Europa, América del Norte y del Sur, África y Asia, cesando a finales de diciembre. El 
último brote localizado en Europa y Norteamérica se extinguió en marzo ${ }^{5}$.

El primer virus de la gripe en humanos se aisló en 1933, por los investigadores Wilson Smith, Christopher Howard Andrewes y P.P. Laidlaw, del Instituto Nacional para la Investigación Médica en Londres, haciendo conocer que la cepa que causó la pandemia de gripe española era modelo $\mathrm{A}$, subtipo $\mathrm{H} 1-\mathrm{N} 1$, de la familia Orthomyxovirus. A partir de 1939 la tasa de mortalidad por esta enfermedad comenzó a descender gracias al uso terapéutico de las sulfamidas y antibióticos, al frenar el avance de las neumonías bacterianas secundarias a la infección viral ${ }^{6}$.

En abril de 2009, en California y Texas (EE.UU.), y en los Estados de Oaxaca y Veracruz (en México), se observaron los primeros casos de pacientes hospitalizados con infecciones respiratorias graves y alta letalidad, lo que alertó a las autoridades sanitarias para identificar la causa, y fue hasta finales de abril que se emitieron informes acerca de un nuevo virus de influenza AH1N1, por lo que más adelante la Organización Mundial de la Salud elevó ese aviso a nivel 5 de pandemia, pues se detectaron casos en todo el mundo?.

En 2003 apareció el síndrome respiratorio agudo grave (SARS) y a fines de 2019 la COVID-19, que ha sido una epidemia devastadora desde el punto de vista sanitario y económico, entre otros aspectos más; en el año 2020 algunos expertos advirtieron de que la mitad de la población mundial estaría infectada por el COVID-19 al final de ese año ${ }^{8}$. Para mayor dificultad en la lucha contra esta pandemia, han surgido nuevas cepas, cada vez más contagiosas y que han afectado a todos los grupos de edad.

Lo cierto es que algunos gobiernos han actuado con mucha tibieza ante la pandemia de COVID-19, o han ignorado su potencial letalidad, exponiendo a la población a sus efectos, ayudado esto, en gran parte, por la pobreza e ignorancia de la gente.
Ya se han desarrollado varias vacunas anti-COVID-19, como Pfizer, Astra-Zeneca, Moderna, Cansino, Sputnik y varias más, que se están aplicando en forma acelerada en muchas partes del planeta, pero mientras las autoridades no den el buen ejemplo utilizando cubrebocas y aplicando la "sana distancia», y la población menosprecie la importancia de la vacunación y no crea en la existencia del coronavirus 2 del síndrome respiratorio agudo grave (SARS-CoV-2), la lucha contra la actual epidemia no tendrá un final a corto plazo.

\section{Financiamiento}

La presente investigación no ha recibido ayudas específicas provenientes de agencias del sector público, sector comercial o entidades sin ánimo de lucro.

\section{Conflicto de intereses}

Los autores declaran no tener conflicto de intereses.

\section{Bibliografía}

1. Watts S. Epidemias y poder. Historia, enfermedad, imperialismo. BarceIona: Editorial Andrés Bello; 1997.

2. Roberts C, Manchester K. The archaeology of disease. Second edition. Cornell University Press; 1999. pp. 136-137.

3. Maradona Hidalgo JA. Historia de las enfermedades infecciosas. Oviedo, España: Universidad de Oviedo; 2010. pp. 97-106.

4. Escobar-Gutiérrez A. Historia de las vacunas y de las vacunaciones. En: Escobar-Gutiérrez A, Valdespino-Gómez JL, Sepúlveda-Amor J, editores. Vacunas ciencia y salud. México: Secretaría de Salud; 1992. p. 21.

5. Sánchez-Fernández LV, Neri-Vela R. Las enfermedades epidémicas de Asturias. De la peste bubónica de 1598/1602 a la gripe de 1918/1919. Oviedo, España: Ilustre Colegio Oficial de Médicos de Asturias; 2019. pp. 155-158.

6. Echeverri-Dávila B. La gripe española. La pandemia de 1918-1919. Centro de Investigaciones Sociológicas. Madrid, España: Siglo XX; 1993. pp. 12-34.

7. Frías-Salcedo JA. Crónicas de la epidemia de influenza AH1N1 en México. 2009-2010. Relato de lo aprendido... Rev Sanid Milit Mex. 2010;64:280-6.

8. Jones DS. History in a crisis-Lessons for COVID-19. N Eng J Med. 2020;382:1681-3. 